\title{
UNA ESPECIE NUEVA DE VIGUIERA (COMPOSITAE, HELIANTHEAE) DEL ESTADO DE QUERÉTARO (MÉXICO)*
}

\author{
Jerzy Rzedowski ${ }^{1}$ y Graciela CALderón DE Rzedowski \\ Instituto de Ecología, A.C., Centro Regional del Bajío, Apdo. postal 386, \\ 61600 Pátzcuaro, Michoacán, México. \\ ${ }^{1}$ Autor para la correspondencia: jerzy.rzedowski@inecol.edu.mx
}

\section{RESUMEN}

Se describe como nueva y se ilustra a Viguiera paneroana, planta sólo conocida de la Sierra Madre Oriental en el estado de Querétaro, de un área próxima al límite con el de San Luis Potosí. De acuerdo con la información proporcionada por el Dr. José L. Panero y el Dr. Edward E. Schilling, las secuencias de ADN indican que la especie se ubica en la base de la sección Maculatae, aunque no pertenece propiamente a ella.

Palabras clave: Heliantheae, México, Viguiera, taxonomía.

\section{ABSTRACT}

Viguiera paneroana is described as new and illustrated. The species is only known from the Sierra Madre Oriental in the state of Querétaro (Mexico), from an area near the border of San Luis Potosí. According to the information supplied by Drs. José L. Panero and Edward E. Schlling, the DNA sequences indicate that the species is located at the base of the section Maculatae, although it does not belong properly to that section.

Key words: Heliantheae, Mexico, Viguiera, taxonomy.

\footnotetext{
* Trabajo realizado con apoyo económico del Instituto de Ecología, A.C. (cuenta 20006), del Consejo Nacional de Ciencia y Tecnología y de la Comisión Nacional para el Conocimiento y Uso de la Biodiversidad.
} 
Las exploraciones realizadas en el noreste del estado de Querétaro han arrojado algunas novedades de su flora fanerogámica. A continuación se describe una especie del género Viguiera encontrada en la Sierra Madre Oriental, en un lugar bastante cercano al límite con el estado de San Luis Potosí.

Viguiera paneroana Rzed. \& Calderón sp. n. Fig. 1.

Herba perennis ca. $1 \mathrm{~m}$ alta; ramuli juvenes piloso-vilosi; folia (saltem superiora) alterna, breviter petiolata, ovata vel anguste ovata (4)6-9 cm longa acuminata denticulata vel subintegra triplinervata supra scabrida, infra viloso-pilosa; capitula pauca; involucrum campanulatum phyllariis 16-24 linearibus vel anguste lanceolatis (6)8-10(12) mm longis subaequalibus vel externis leviter brevioribus; paleae oblongae plerumque obtusae; flores radii 5-8 laminis oblongis vel oblanceolatis 2.2-2.8 cm longis luteis; flores disci 80-120 corollis ca. $6 \mathrm{~mm}$ longis luteis; achenia oblonga applanata ca. $2.5 \mathrm{~mm}$ longa, pappus aristis 2, ca. $2 \mathrm{~mm}$ longis et squamellis ca. $10,1 \mathrm{~mm}$ vel minus longis.

Planta herbácea perenne de ca. $1 \mathrm{~m}$ de alto; ramillas café-rojizas, piloso-vilosas con pelos de ca. $1 \mathrm{~mm}$ de largo, glabrescentes con la edad; hojas, al menos las superiores, alternas, peciolo de 3 a $9 \mathrm{~mm}$ de largo, con pubescencia similar a la de las ramillas, lámina ovada a angostamente ovada, de (4)6 a $9 \mathrm{~cm}$ de largo, de (2)2.5 a $3.5 \mathrm{~cm}$ de ancho, ápice acuminado, base cuneada a redondeada, margen esparcidamente denticulado a casi entero, de textura membranácea, esencialmente triplinervadas, aunque con un par de nervaduras menos conspicuas partiendo muy cerca de la base de la lámina, haz de color verde olivo, escábrido y rasposo al tacto, envés más pálido y viloso-piloso sobre las principales nervaduras, con numerosos puntos glandulosos; cabezuelas dispuestas por pocas ( 3 a 8 ) en conjuntos cimosos terminales corimbiformes; involucro campanulado, sus brácteas 16 a 24, de tamaño subigual, o bien, las exteriores un poco más cortas que las interiores, dispuestas en 2 a 3 series, lineares a angostamente lanceoladas, de (6) 8 a 10(12) mm de largo, puntiagudas en el ápice, piloso-vilosas por fuera, aunque algunas de las interiores se observan casi glabras en la superficie y sólo llevan pelos en los márgenes, de textura herbácea, receptáculo cónico, páleas oblongas, de ca. $6 \mathrm{~mm}$ de largo, por lo general romas en el ápice, pilósulas y/o ciliadas en la porción distal, rodeando estrechamente las flores del disco; flores liguladas 5 a 8 , estériles, sus láminas oblongas a oblanceoladas, de 2.2 a $2.8 \mathrm{~cm}$ de largo, amarillas, pubérulas sobre las nervaduras por fuera; flores del disco 80 a 120, sus corolas de ca. 6 mm de largo, de las cuales menos de $1 \mathrm{~mm}$ corresponde al tubo y poco más de $1 \mathrm{~mm}$ a los lóbulos, amarillas, hispídulas en los lóbulos por fuera, anteras de ca. $2.5 \mathrm{~mm}$ de lar- 
Rzedowski y Calderón de Rzedowski: Una especie nueva de Viguiera del estado de Querétaro, México

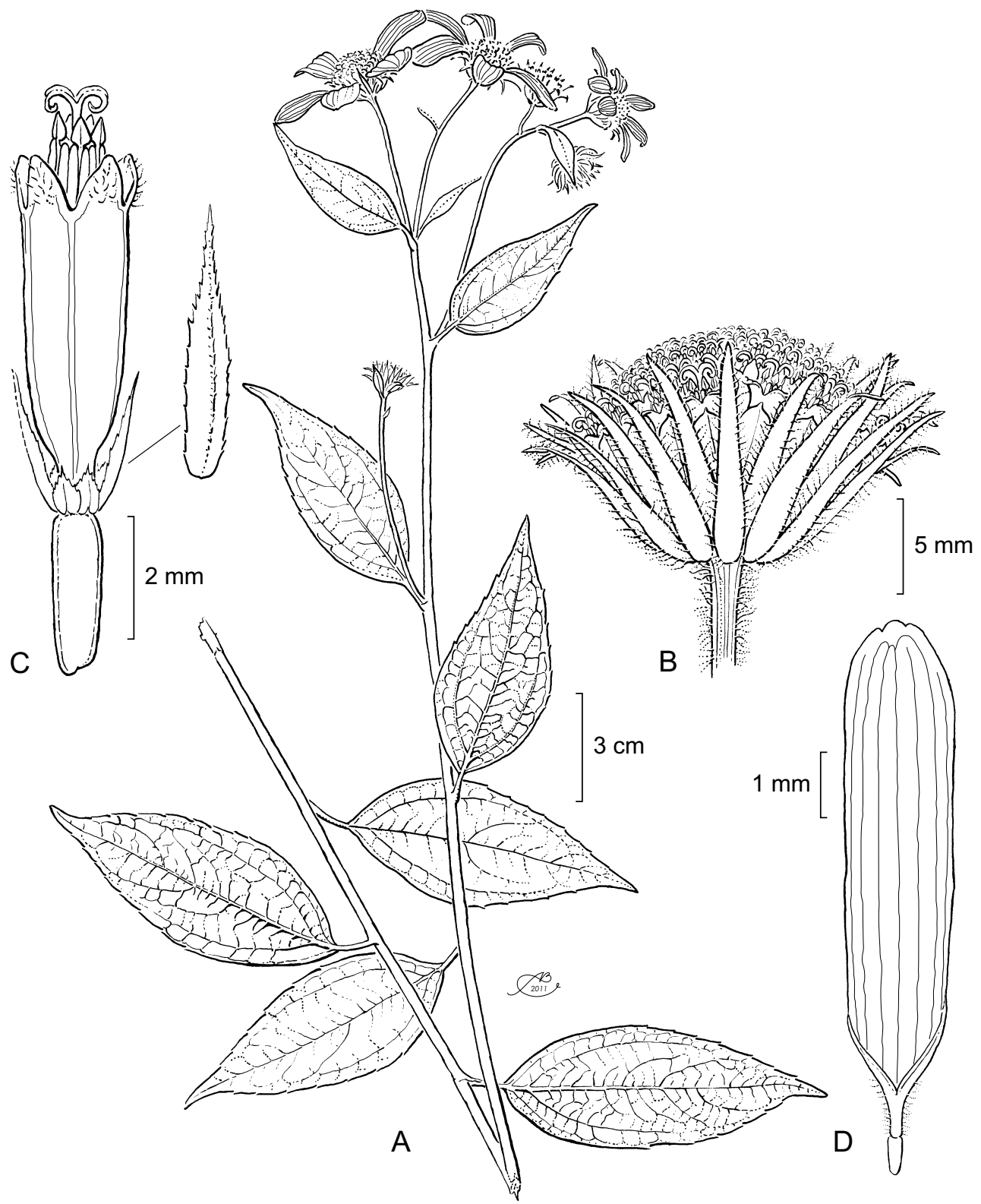

Fig. 1. Viguiera paneroana Rzed. \& Calderón. A. rama con hojas y cabezuelas; B. cabezuela desprovista de lígulas; C. flor del disco; D. flor ligulada. Ilustrado por Alfonso Barbosa. 
go, negruzcas, ramas del estilo lineares, ensanchadas y finalmente agudas en el ápice; aquenios oblongos, comprimidos, de ca. $3.5 \mathrm{~mm}$ de largo, cafés-oscuros o negruzcos, hispídulos hacia el ápice, vilano de 2 aristas de ca. $2 \mathrm{~mm}$ de largo, ensanchadas en la base y muy pronto caedizas, así como de ca. 10 escamitas de $1 \mathrm{~mm}$ o menos de largo.

Holotipo: México, Querétaro, entre El Llano Chiquito y La Lagunita de San Diego, municipio de Landa, bosque de Cupressus, Pinus, Abies sobre laderas calizas, alt. 2250 m, 14.X.1999, S. Zamudio y E. Carranza 11215 (IEB), isotipos por distribuirse.

La especie sólo se conoce de esta colecta, donde se registra como abundante. Aparentemente representa un estrecho endemismo de un corto segmento de la Sierra Madre Oriental.

El nombre del taxon nuevo se dedica al Dr. José L. Panero, ameritado botánico consagrado al estudio de la familia Compositae y con particular interés en el conocimiento de Viguiera y grupos relacionados.

El Dr. Panero tuvo la amabilidad de examinar con detalle un ejemplar de la planta que se describe y confirmar su condición de especie aún sin dar a conocer. No se limitó a lo anterior, sino en una fracción del material de estudio analizó las secuencias de ADN y envió los resultados a su estrecho colaborador el Dr. Edward E. Schilling, quien los sometió a programas de filogenia. Como resultado llegó a la conclusión de que la especie nueva se encuentra en la base (aunque sin pertenecer propiamente allí) de Dendroviguiera, grupo que Panero y Schilling (1988) habían revisado esencialmente con anterioridad como Viguiera sección Maculatae.

De acuerdo con la reciente comunicación del Dr. Panero, Dendroviguiera es uno de los géneros que los mencionados autores están proponiendo en el proceso del desmembramiento del conjunto polifilético que tradicionalmente se ha considerado como parte de Viguiera.

De hecho, $V$. paneroana se asemeja a varios miembros de la sección Maculatae en la forma y en la estructura del involucro, de las páleas, de las hojas, del vilano y de la corola, pero a diferencia de ellos es una planta herbácea.

\section{LITERATURA CITADA}

Panero, J. L. \& E. E. Schilling. 1988. Revision of Viguiera sect. Maculatae (Asteraceae: Heliantheae). Syst. Bot. 13(3): 371-406.

Recibido en junio de 2011. Aceptado en julio de 2011. 